\title{
A Resident's Guide to the Art of Persuading those who Judge You at the Surgical M\&M Conference
}

\author{
Paul J. Schenarts*, Michael P. Meara and Brett H. Waibel
}

Division of Surgical Education, Department of Surgery, Brody School of Medicine, East Carolina University, USA

\begin{abstract}
The M\&M conference is a corner stone of surgical education. Frequently, this conference requires the resident to effectively put forth an argument why the supervising attending made particular decisions. As such a resident's performance is based not only on factual knowledge but also on his or her understanding of the basic principles of argumentation, persuasion and the art of oral argument. This manuscript provides a basic overview of these principles.

The morbidity and mortality conference (M\&M) is a cornerstone of surgical education. Probing of the depths of the resident's fund of knowledge, identifying areas of misunderstanding and improving critical reasoning skills are unquestionably fundamental to the development of a surgeon.
\end{abstract}

Accountability is an essential surgical value and constitutes another important aspect of this conference. While at times the focus of an M\&M presentation is on holding the resident accountable for his or her individual actions. More frequently, the M\&M conference resembles a court room in which the resident is put in the position of representing a faculty member and articulating the rationale for the decisions made by that faculty member. In this process, the resident acts similar to a lawyer, who is charged with persuading judges (other faculty members) that the decisions of the supervising faculty were appropriate. While the resident may have executed the decisions, the resident's ability to defend these decisions has a direct impact on the resident's professional reputation and written evaluations. To carry this analogy further, the M\&M conference may also include the presence of opposing counsel, in the form of adversarial faculty; who may be in a direct competitive relationship with the faculty member whom the resident is representing.

Given the premise that the M\&M conference is reflective of a court of law, there may be valuable lesions surgical residents could learn from the legal scholars. Recently, Associate Justice of the Supreme Court of the United States, Antonin Scalia and legal scholar Bryan A. Garner, have published a useful guide on how effective advocates persuade courts to decide cases in favor of their clients [1]. In particular, the sections on the principles of persuasion, argumentation, and the art of oral argument offer useful advice which could be translated for surgical residents as they prepare to present at the M\&M conference. The principles outlined in their book serve as the foundation of this manuscript and have been adapted to meet the needs of surgical residents. The recommendations that follow are not based on objective scientific data. This logical framework, however, provides a useful guide for residents who wish to improve the quality of their M\&M presentations.

\section{Basic Principles of Persuasion \& Argumentation}

It is commonly understood that the resident is not ultimately responsible for clinical decision-making, however, that fact may be forgotten during the $M \& M$ presentation. As a result the resident's reputation is significantly influenced by his or her ability to put forth a strong argument why an attending surgeon decided on a particular course of action. It is possible for a resident to have a good fund of factual knowledge but still not effectively represent the decisions of the faculty. Therefore residents would benefit from understanding a few basic principles of persuasion and argumentation.

Make logical sense: The factual premises must be well founded and your reasoning must logically compel the actions that were taken. All sorts of extraneous factors-emotions, biases, perceptions-may have influenced the clinical decisions; however, these will do little to strengthen your position before an objective audience.

Establish yourself as trustworthy: An ever-present factor is the human proclivity to be more receptive to an argument from a person who is trusted. Be scrupulously accurate. Trust is immediately lost by conveying false information-not just intentionally but also through carelessness. If you are estimating a data point, it is better to say outright that you do not recall the exact data but you recall it to be approximately "X". In these days of the electronic medical record, it is possible that those in the audience may have the chart right in front of them. Above all maintain an even, good-humored temperament.

Know your audience: Learn as much as you can about those in the audience. In particular know who your adversaries are and what leads them to draw particular conclusions. For example if your faculty tends to be impatient, pare down your arguments to make them especially terse and pointed.

Know your case and lead with your strongest points: Do not underestimate the importance of facts and your own knowledge base. Your first step in preparing for M\&M is to become an expert on every aspect of the case and what factors drove the decision-making. Discussing the factors which led to particular decisions with the supervising faculty is a must. Best practice would be to discuss them before or immediately after a complication has occurred, rather than the evening before the presentation. During any presentation, attention will be greatest at the outset. Therefore present the background

*Corresponding author: Paul J. Schenarts Director, Professor of Surgery ,General Surgery Residency, Assistant Dean for Clinical Academic Affairs Associate, Division of Surgical Education, Department of Surgery Brody School of Medicine, East Carolina University 600 Moye Ave Greenville, NC 27858, Tel: 252847-4299; Fax : 252-847-8208; E-mail: pschenar@pcmh.com

Received November 28, 2011; Accepted December 21, 2011; Published December 22, 2011

Citation: Schenarts PJ, Meara MP, Waibel BH (2011) A Resident's Guide to the Art of Persuading those who Judge You at the Surgical M\&M Conference. Surgery 1:105. doi:10.4172/2161-1076.1000105

Copyright: (c) 2011 Schenarts PJ, et al. This is an open-access article distributed under the terms of the Creative Commons Attribution License, which permits unrestricted use, distribution, and reproduction in any medium, provided the original author and source are credited. 
information quickly. While you should be knowledgeable of all the facts, not every fact needs to be included. Present a logical story line but get right to the complication. Once you're at the major decision point, lead with the strongest reasons why a particular action was taken. A scatter shot argument that is needlessly expansive leaves the impression that the presenter lacks of knowledge or organized thinking.

Anticipate your adversary's questions and refute arguments in advance: Try to discern the real argument an intelligent opponent would make. Acknowledge and incorporate these into your presentation, thereby dispatching these potential alternative actions on your own terms. If you wait to until the question period to address your weaknesses the audience will focus on your opponents' arguments. Further, responding only after you have been challenged makes it appear that you did not know the alternatives or that you are reluctant to address weaknesses in the decision-making. Addressing your weaknesses on the front-end will give the impression that you are knowledgeable, even-handed and trustworthy. Finally, by systematically demolishing counterarguments during the presentation, you turn the tables and put your opponent on the defensive.

Be rational not emotional: People in general and surgeons in particular, pride themselves on being rational not emotional. Appealing to emotions or biases that are not evidenced-based is fraught with danger. Cultivate a tone of rationality. In particular, always be respectful of the faculty, even if you believe they are incorrect. Appearing defensive or combative will be perceived as a sign of weakness.

Do not try to defend the indefensible: If mistakes were made, address them on your own terms by incorporating them into your presentation early. Do not wait until the question period. This avoids the impression that you have tried to sweep unfavorable factors under the rug. Second, it demonstrates that you are a reasonable, trustworthy resident, who has carefully reviewed the case. Do not hide from mistakes, rather boldly demonstrate acceptance of them. In essence this will steal the thunder from those who wish to debase you, while simultaneously enhancing your personal creditability.

\section{The art of oral argument during $M \& M$}

Despite visual aids such as power point, radiographs and photographs of pathology specimens, the surgical M\&M conference is basically an oral argument. Therefore surgical residents must develop their verbal presentation skills. This requires preparation before the presentation, a flawless execution of the presentation, and most importantly the ability to handle questions and unforeseen weaknesses in the decision-making.

\section{Before you present your case}

Prepare to be a public speaker: While speaking before an audience may be anxiety provoking, it is as much a requirement of surgical training as knowing the steps of a Whipple procedure. To be an effective public speaker requires deliberate practice and preparation. One of the most common mistakes is speaking too quickly. People can only process information at a moderate rate. Therefore a rapid fire presentation, even if it is complete, is often perceived as ineffective. Working on slowing down the presentation is likely to be difficult but certainly worth the trouble. Learn to lower the pitch of your voice, as a high, shrill tone does not inspire confidence. Speak distinctly. It does not matter what you said, what matters is what was heard. Purge your speech of "ums" and "errs", rather if necessary simply, pause between words. Perhaps the rhetorical device most undervalued and ignored is the pause. A strategic pause after an appropriate lead-in will emphasize whatever phrase or sentence immediately follows. In speaking the resident needs to cultivate a stage presence similar to that of an actor.
Master the proper pronunciation of English words and surgical terminology: As a surgical resident, it is imperative that you speak like a surgeon. You will be thought of as sophisticated or simple-minded, knowledgeable or ignorant, not just by what you say but also how you say it. Use professional terms and avoid slang at all costs.

Prepare assiduously: The most difficult element of an oral argument is the unexpected argument from an adversary. Ensure to the maximal extent possible that these surprises do not occur. Not only does this imply that you know all the facts and details of the medical record, you must also think about the case from various perspectives. Consider the common questions but also prepare for tangentially related questions and hypothetical situations. In particular, be prepared by knowing the weaknesses of your adversary's alternatives and develop an evidencebased response to defend your decision-making. As for the facts within the medical record, your knowledge must be utterly complete and meticulously organized. Learn the record in its entirety but distill what relevant information you will present. Address only the most important elements of your case in depth.

Organize your presentation. Whereas it is unwise to write out an entire script, the effective use of an outline or key points may be very helpful. When standing at the podium, fumbling through papers or trying to pull up computer images, not only wastes time; it makes you appear unprepared. One suggestion is to down load key images into a slide presentation in advance. Another suggestion is to write your outline on the inside of a manila folder with no papers inside. This strategy prevents papers from getting lost.

Present a mock M\&M to people who are not sympathetic to your case: As stated above, during the preparation phase it is important to review the rationale behind key decision points with the attending of record. However, this attending will be sympathetic to your case and you will need to be prepared for adversaries, who may not agree with your faculty's course of action. One effective strategy is to present your case in advance to the harshest critic in the room. This accomplishes two things. First, you receive a valuable education as to alternatives. Second, you will have taken the fire out of his belly and hence he will be less likely to attack you during M\&M.

\section{The presentation}

Arrive early: The proper frame of mind for an oral argument is a calm concentration. A last-minute, frenetic rush into the M\&M conference room is not conducive to this attitude. If it is possible some thing can go wrong, it will. If you are presenting at a new institution, know what equipment is available and how to use it.

First impression: Even before you utter your first word, the audience will start to make judgments, as to your professionalism and preparedness. While waiting for the proceedings to begin, conduct yourself in a serious manner. Obviously dress in a conservative matter. Traditionally surgeons are not known for trendy outfits or loud ties. While awaiting your case sit erect and appear to have an air of sober anticipation. When your case is called approach the podium with a brisk business-like manner.

Giving the presentation: Remember the relationship you want to establish is that of a junior partner addressing a senior partner. So be conversational but not familiar. Don't be excessively deferential nor off-handed and chummy. Focus quickly on the most crucial elements that went into you decision-making. Concentrate your fire on your strongest points. Treasure simplicity during the presentation but know the details if asked. Don't read a presentation but also don't give one from memory. Avoid distracting mannerisms. Be cautious about 
humor, you are probably not as funny as you think you are. Use visual aids carefully to illustrate key factors or elements of the presentation. Excessive employment of these visual aids may be interpreted as avoidance of discussing the complication. Be flexible and be ready to be interrupted. If you think you will present your case without interruption you will fare poorly. Even if disrupted it is important that you remain organized and hit upon all the key points that went into your decisionmaking. Finally finish your presentation with a strong conclusion which incorporates what you would have done differently. The most conservative play is to clearly state what the errors were and how you would attempt to prevent them in the future. Ending a presentation by blaming the patient's disease, may result in the appearance that you have abdicated your responsibility.

\section{Handling questions}

In most Surgical M\&Ms more time is spent in the discussion of the case rather than in its formal presentation. In the authors' opinion, it is the ability of the presenter to respond to questions that separates excellent presentations from the mediocre. It is also during this section of an M\&M that the resident is most on stage and from a reputation standpoint has the most to gain (or the most to lose). Therefore residents should welcome questions-avoid and appearing defensive.

Anticipate your weaknesses and handle them on your own terms: As stated earlier in this manuscript, if the resident has properly prepared, the potential weaknesses in the decision-making have already been addressed in the presentation. However, that does not mean the question will not be raised again. If it does, politely respond using the same rational given during the presentation. It is important that the reasoning and logic remain internally consistent during both the presentation and the question period.

Listen to the question: The presenter appears incompetent, when launching into the answer of a question that is entirely different than the one asked. If the question is not clear, ask for clarification and answer the question asked. In addition, listen closely to the discussion among the faculty and questions they ask each other. Not only may you get the same question, but also because the general line of inquiry suggests what the principal concerns of the faculty may be. Avoid responding to a question that has not been asked. As a resident you have enough to worry about, do not open the door to additional questions if you do not have to.

Responding to a question: When appropriate begin your response with a direct "yes" or "no" and then follow with whatever qualification or explanation is required. If you do not know the answer, say so. If you make an attempt to answer a question but you are unsure, respond with a strong, yet qualified response. (I believe the answer is yes, but I am not entirely sure."). Never postpone an answer to a direct question, Be prepared for tangential questions, related scenarios and hypothetical situations. This was part of your preparation, so should be relatively easy to handle. Finally, never speak over the person asking the question.

"The difficult judge" As is well known to every surgical resident, some faculty members can be particularly challenging. When facing off against one of these, do not display your discomfort. Avoid looking down, rather look them straight in the eye and respond is a clear, articulate, and unemotional, firm professional manner. Confront the question as best you can and try to move on. If the questioner continues to press you on the same point and you are unable to say anything more, devise a polite, professional way to end this exchange. It would certainly be appropriate to say "I respectfully can not respond other than what I have already said". One suggestion to counter these individuals is to use time at M\&M when not presenting to study what makes these difficult faculty members tick. What are their "hot button" issues? Then when presenting a case that touches on one of these "hot buttons" you will be best prepared.

Recognize the friendly question: The majority of questions a surgical resident receives will be an attempt to probe the weakness of his or her knowledge base or to further investigate the elements that went into the decision-making, but not all of them. Occasionally, especially when the resident is being pressed hard by a faculty member, another member of the faculty will try to give you a helping hand by asking a relatively easy question or one that vindicates your earlier answer as correct. It is the height of ingratitude to mistake this friendly gesture as hostile.

\section{After the presentation}

The essence of the surgical M\&M conference is education. Shortly after your presentation is complete it is important that you discuss the presentation with your attending surgeon to ensure you hit all the pertinent points. More importantly, it is important to review each aspect of your presentation with a senior resident or mentor to identify areas in which you could be better prepared.

In conclusion, performance at the surgical M\&M conference has a direct effect on the public reputation of the surgical resident. While the complications presented at this conference are occasionally directly attributable the actions of an individual resident, the majority of presentations require the resident to effectively make an oral argument on behalf of the supervising faculty.

\section{References}

1. Scalia A, Garner BA (2009) Making your case: the art of persuading judges. 